\title{
Humanitats digitals i pedagogies culturals: mirades creuades als entorns educatius híbrids
}

\author{
Ricard Huerta * \\ Cristóbal Suárez ${ }^{* *}$
}

\section{Resum}

Les humanitats i les arts estan vivint un procés ràpid d'evolució i de canvis gràcies al creixement de l'univers digital. L'educació no està exempta de viure transformacions profundes, motivades igualment per l'impacte d'aquesta realitat virtual que ja és local i global, que és ubiqua, i que ens afecta a tots. Com a docents i formadors de docents, ens inserim en aquest procés per tal d'analitzar fins a quin punt les hibridacions d'ambdós escenaris (les humanitats digitals i les pedagogies culturals) estan afavorint un clima integrador i de superacions, o bé propicien un nou model d'abusos i excessos cap al professorat i l'alumnat de les diferents etapes educatives. Mirant la situació en positiu, observem que la petjada digital pot ajudar a trencar les barreres tradicionals que havien estat marcades per les àrees de coneixement específiques, superant així l'encasellament tradicional de matèries i assignatures concretes, possibilitant escenaris connectats des de la transversalitat. És per això que ens interessa conèixer els diferents models híbrids que afavoreix l'entramat digital, implicant artistes, educadors en arts, historiadors, lingüistes i dissenyadors, que ens mostren les seves particulars visions d'aquest nou model d'escenaris educatius connectats.

\section{Paraules clau}

humanitats digitals, pedagogies culturals, art, educació, formació del professorat, gènere.

Recepció original: 18 de novembre de 2019

Acceptació: 06 de març de 2020

Publicació: 30 de juny de 2020

\section{Introducció ${ }^{1}$}

En primer lloc caldria definir per separat els conceptes d'humanitats digitals i pedagogies culturals. Si bé es tracta de termes amb un significat ampli, sí que tenim la possibilitat d'observar una evolució clara del que ocorre en cadascun d'aquests àmbits. Les humanitats digitals s'estan desenvolupant especialment en àmbits acadèmics com la lingüística, la literatura, la història, la filosofia o la història de l'art. El començament d'aquest procés cap a l'escenari virtual va estar molt marcat per l'interès envers la digitalització de documents i arxius, ja que els processadors informàtics han incorporat a l'arxivística i la documentació nous arguments de caire integrador, generant connexions constants a escala mundial, motiu pel qual actualment tenim al nostre abast en Internet tot un món de possibilitats d'accés a museus, arxius, biblioteques i bases de dades. Però aquest afany arxivístic i documental ha donat pas també, gràcies a les tecnologies a l'abast del gran públic

(*) Catedràtic d'Educació Artística de la Universitat de València. Director del Grup CREARI de Recerca en pedagogies culturals (GIUV2013-103). Adreça electrònica: ricard.huerta@uv.es

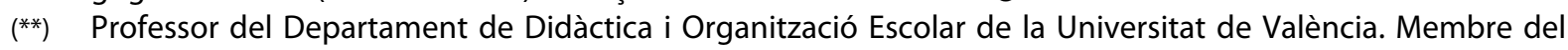
Grup CREARI de Recerca en pedagogies culturals (GIUV2013-103). Adreça electrònica: cristobal.suarez@uv.es

(1) Aquesta investigació ha rebut el suport de la Conselleria d'Innovació, Universitats, Ciència i Societat Digital de la Generalitat Valenciana, a través del Programa per a la promoció de la Investigació Científica, el desenvolupament tecnològic i la innovació amb referència AORG2019-044. 
i a l'ús massiu de dispositius mòbils, a noves formes d'acostar-nos a la literatura, l'art, la música, la història, la filosofia i la creació en general. És per això que hem d'observar aquest fenomen com un fet de gran repercussió i d'àmbit global. Si bé els estats i les nacions, així com els corresponents governs regionals, continuen tenint molt de pes en la difusió mediàtica i l'engranatge cultural, el ben cert és que Internet ha propiciat un salt qualitatiu pel que fa a les relacions d'àmbit global, de manera que les persones tenim accés a connexions amb gent de tot arreu, i per tant també la possibilitat de generar processos comunicatius en xarxa vinculats a l'estudi i la divulgació de les humanitats. No es tracta de pensar que els teclats i les pantalles han substituït al Ilibre o el periòdic en paper, sinó que els models de producció i difusió de la cultura ja no es regeixen per un argument lineal, sinó que s'evidencien en tant que xarxes connectades. Pel que fa a les pedagogies culturals, hem d'admetre que ja no eduquem igual com ho fèiem abans, ni aprenem de la mateixa manera. Ara disposem de nous mecanismes que afavoreixen dinàmiques més fluides i ràpides, més ambicioses si cap, però sobretot més complexes. El paper del professorat i de l'alumnat evoluciona cap a models híbrids, flexibles, ubics i permeables. L'educació digital ja és un fet assumit, i per tant caldrà avançar cap a noves militàncies més flexibles. La cultura es viu i es comunica, però sobretot s'aprèn, igual com la sensibilitat i el respecte. Per tant, haurem de gestionar noves perspectives culturals i pedagògiques que posen en valor les realitats emergents.

\section{Percepcions de futurs docents sobre els hàbits digitals}

El treball de Ricardo Domínguez ens parla de les percepcions dels estudiants cap a l'ús i l'aprofitament tecnològic en les pràctiques quotidianes a l'aula. Domínguez, especialista en ús de les TIC a l'ensenyament secundari (Huerta i Domínguez, 2011), però també coneixedor de la realitat a educació primària (és assessor de l'Àrea de Tecnologia al Cefire de València), insisteix en el paper rellevant que hauria d'adquirir la tecnologia en els contextos educatius, però adverteix també dels prejudicis que s'hi han instal.lat entre el propi professorat (Domínguez, 2019). El seu estudi indaga en el valor que té per a l'alumnat l'ús de recursos tecnològics, incidint en l'alumnat de grau de primària i del màster de professorat de secundària, futurs docents, ja que Domínguez imparteix classes a la universitat en la formació inicial de futur professorat d'educació artística. Per al cas aplica una metodologia mixta o plural, amb un enfocament més quantitatiu, aplicant un estudi de cas amb una finalitat descriptiva (Yin, 2009). De l'estudi que ens ofereix Domínguez, considerem summament important el fet de creuar les possibilitats actuals de les arts visuals (humanitats digitals) amb la pràctica docent en la qual intervé de manera determinant la cultura visual (pedagogies culturals). L'autor arriba a l'extrem d'afirmar que si bé hi ha una predisposició inicial cap a l'ús de les tecnologies en els processos d'ensenyamentaprenentatge, el ben cert és que finalment aquesta percepció positiva inicial es transforma en actitud hostil quan revisem i observem detingudament les pràctiques habituals dels docents a les aules. De fet, constatem que les dificultats inicials (falta d'infraestructures adequades, manca de suport tècnic, debilitat de l'estructura organitzativa dels centres, necessitat de capacitació i major competència digital del professorat) no són superades per falta de major implicació del propi professorat, que pateix una pressió administrativa i curricular profundament contrària i aliena als avenços tecnològics.

Degut a aquesta situació anòmala, la percepció de l'alumnat és que a les aules hi ha una manca important d'aprofitament tecnològic. No hauria de ser així, caldria reconsiderar seriosament què estem fent a l'aula amb les tecnologies digitals, i meditar de quina 
manera podem avançar en positiu al respecte. La tecnologia en ella mateix no significa res, ara bé, haurem d'assumir que les TIC han envaït l'espai de la comunicació a tots els nivells, i l'entorn curricular no pot romandre aliè a aquesta realitat que és quotidiana i és global. Domínguez ens recorda que en la major part de les investigacions s'afirma que existeix una correspondència entre les creences sobre l'ús de les tecnologies i la manera en què aquestes són implementades en els processos d'ensenyament-aprenentatge, i del caràcter bidireccional entre creences i pràctica educativa. És per això que les actituds i percepcions positives cap a les tecnologies digitals estableixen condicions favorables per al seu ús a l'aula, mentre que una percepció negativa inhibeix de la seva utilització. Per tant, en la formació de docents hem d'incorporar una adequada capacitació en la competència digital, introduint espais de reflexió que ens permetran analitzar les creences dels docents al voltant de l'ús educatiu de les TIC.

Després d'un estudi minuciós i estricte, Domínguez detecta que els aspectes millor valorats per l'alumnat de magisteri pel que fa a l'ús de les TIC són: que faciliten l'intercanvi d'informació a través de diferents mitjans; que resulten fonamentals en la formació permanent del docent; i que les aportacions personals en la xarxa poden afavorir l'aprenentatge d'altres persones. Per contra, els aspectes pitjor valorats de l'ús de les TIC són: que la diversitat de serveis en la xarxa dificulta la gestió dels seus continguts; que suposen una càrrega de treball addicional; i que l'exposició pública dels processos d'aprenentatge limita la llibertat d'expressió. A més, s'hi detecta que els futurs docents tenen una valoració positiva de les TIC tot coincidint amb els resultats d'altres estudis (Roig-Vila, MengualAndrés, Sterrantino i Quinto, 2015; Suárez-Guerrero, Lloret-Catalá i Mengual-Andrés, 2016). Aquest alumnat en formació, que seran futurs docents, valora positivament de les TIC que faciliten l'intercanvi d'informació a través de diferents mitjans, ja que resulten fonamentals en la formació permanent del docent. Critiquen també que la diversitat de serveis en la xarxa dificulta la gestió dels seus continguts, afegint una càrrega de treball addicional. Atenent als resultats de la investigació, resulta evident que cal desenvolupar estratègies adequades basades fonamentalment en l'ús adequat de les TIC. Gràcies a l'estudi es comprova que no existeixen diferències estadísticament significatives en la percepció sobre les TIC en funció del gènere, si bé la percepció sobre el valor de les TIC és més positiva per part de les dones que dels homes.

\section{Una nova generació de mestres que ara són estudiants}

Segons ens planteja Dan Levin (2019), l'actual alumnat universitari pertany a una generació particularment rica i complexa, a l'igual que els temps i contextos actuals. Per a Lander Calvelhe, el futur professorat d'educació infantil i primària pertany majoritàriament a la generació $Z$, ja que es tracta d'alumnat que té actualment una mitjana de 20 anys. La formació sobre art i educació d'aquest alumnat universitari possibilita una àmplia varietat de continguts i d'experiències igualment diverses, que poden atendre tant a les seves pròpies característiques generacionals en tant que estudiants, com a la seva formació com a docents del futur. Calvelhe presenta una sèrie de qüestions que relacionen els resultats de diversos estudis de mercat i de publicitat al voltant de la generació $Z$, amb la seva pròpia pràctica docent universitària.

En termes generals, aquesta generació $Z$ es defineix per estar composta de genuïns nadius digitals de l'era de la informació globalitzada. El seu dèficit d'atenció és alarmant; tenen una alta dependència a la tecnologia, i utilitzen els seus telèfons intel.ligents una 
mitjana de 4 hores al dia. És una generació acurada a l'hora de compartir la seva intimitat a Internet, principalment degut a que les xarxes socials són cada vegada més diverses i sofisticades. La majoria d'aquests joves pot arribar a gestionar fins a 5 dispositius audiovisuals alhora amb sorprenent habilitat. Per aquests i altres motius, pot resultar particularment difícil connectar amb els joves d'aquesta generació $Z$, precisament per haver nascut amb tecnologia digital a l'abast i per disposar d'innombrables continguts audiovisuals.

Es planteja Lander Calvelhe si els professionals de l'educació també hauríem de preguntar-nos fins a quin punt ens afecta aquesta problemàtica. Com podem connectar amb la generació $Z$, tenint en compte que és tan diferent a l'alumnat habitual de la cultura escolar tradicional? Com podem capgirar aquestes característiques i hàbits en favor d'un desenvolupament d'aprenentatges holístics i emancipadors, especialment quan es tracta de la formació del futur professorat? Haurem d'atendre a les característiques concretes i actuals dels estudiants que han pres la decisió de formar-se com a futurs docents (Trifonas i Jagger, 2019). A més, no podem perdre de vista que des del món empresarial s'estan invertint quantiosos recursos en estudiar els mercats, conèixer qui i com són els seus futurs clients, i investigant sobre les possibles maneres de connectar amb aquesta joventut (Francis i Hoefel, 2018).

Nombrosos docents han explorat i reflexionat sobre què pot aprendre l'educació de les arts, tant en les seves formes de fer, com en els seus continguts i les seves potencialitats. Ser docents de la generació Z no pot implicar únicament la integració de les tecnologies a l'aula, sinó que també és pertinent oferir espais creatius i innovadors d'aprenentatge amb metodologies visuals d'ensenyament i interacció. Calvelhe defensa la utilització d'elements molt pròxims a la generació $X$ com són la música i l'humor, argumentant que allò veritablement important no és el «què» (en aquest cas l'ús dels engranatges visuals), sinó el «com» i el «per què», és a dir, la perspectiva educativa i la seva implementació metodològica per disposar d'uns objectius o fonaments. L'impacte positiu de les arts en l'educació, tant en els ensenyaments de les pròpies arts (dibuix, pintura, fotografia, etc.) com a través d'elles, s'evidencia en el desenvolupament de programes d'educació artística de qualitat. D'aquesta manera milloren els resultats acadèmics de l'alumnat, la seva autoestima i pensament crític, permetent que tant estudiants, com famílies, inclús el propi barri, tinguin una millor percepció i actitud cap al centre educatiu, promovent la cooperació, la tolerància, i el sentit de responsabilitat de tota la comunitat educativa. També adverteix Calvelhe que cal tenir cura dels petits detalls, per exemple dels materials, el color i la mida de la lletra, la resolució de les imatges que s'utilitzen, etc. i així permetre que aquesta cura impregne la resta de l'acció docent.

Tenint en compte l'entorn socioeconòmic, cultural i tecnològic que ha anat dibuixant la generació $Z$, trobem professorat que ja s'ha preguntat com dur a terme la seva tasca docent amb aquesta generació (Cilliers, 2017). Cal augmentar la motivació per part del professorat, amb mètodes d'ensenyament efectius que donin menys importància a la lectura i més poder a l'acció de fer, fins i tot a l'activitat física i el moviment, així com a la cooperació. Una persona que ha nascut en un món globalitzat i interconnectat viu i respira tecnologia, una realitat que s'expandeix en la seva vida escolar. Els estudiants universitaris de la generació $Z$ prenen notes en els seus ordinadors o altres dispositius digitals, fan més preguntes per correu electrònic que a l'aula, sense esperar que li contesten, i la seva actitud a classe i davant el professorat és ben diferent al que estàvem acostumats. 
El repte és impressionant, i afecta no solament a la tecnologia digital, sinó també als entorns educatius que transitem (Huerta i Alonso-Sanz, 2017). Si assumim que no hi ha una fórmula màgica per captar l'atenció d'aquesta generació, la clau pot estar en la creativitat. En aquest sentit, sempre segons Calvelhe, caldrà fer ús de la música i de l'humor, utilitzar una estètica acurada, atendre a la diversitat, oferir interacció, i ser autèntics.

\section{Propiciant un ús sensible de la fotografia i els dispositius mòbils}

El desenvolupament de l'imaginari cultural que implica allò que anomenem cultura digital seria impensable sense la construcció d'un imaginari visual d'una càrrega estètica que viatja en múltiples direccions i que es converteix en el fil invisible que uneix tota l'estructura, assegura Ricard Ramon al seu text «Interseccions entre imatge, art i tecnologia per a la construcció de coneixements sensibles». Per dotar de sentit les dimensions del coneixement que naixen i es nodreixen en el magma de l'univers digital i tecnològic, l'estètica esdevé un instrument al servei de les nostres interaccions, un mitjà al servei d'un aprenentatge del món. Segons l'autor, quan ens referim a món, ho fem en un sentit ampli i multidimensional del terme, més enllà de l'espai físic sobre el qual habitem inevitablement. Parlem dels mons que construïm i que ens permeten desenvolupar-nos com a éssers humans, i entre ells els mons vinculats a la cultura digital, mons sensibles, simbòlics i múltiples, que esdevenen el mitjà a través del qual creem connexions que ens permeten comprendre'ns a nosaltres en relació amb la resta. Mirat així, i sempre segons Ricard Ramon, des d'una perspectiva educativa, la tecnologia esdevé un constructe simbòlic a través del qual elaborem representacions dels mons possibles, i ho fem principalment per mitjà de les arts, de l'experiència estètica i de les imatges. Tot això no deixa de ser una experiència que es vincula a un aprenentatge a través de les arts, que en realitat té una funció molt clara: comprendre el món en la seva complexitat i diversitat.

Atenent al valor simbòlic de les imatges, podem valorar que la fotografia, des del punt de vista de la cultura contemporània, no s'entén sense el desenvolupament tecnològic, al mateix temps que aquest tampoc podria tenir una lectura humana de no ser per la fotografia, i que tot això està emmarcat en un espectre de comprensió del món i de creació de coneixement com són les arts. Segons Ramon, les tecnologies digitals estan connectades amb els ritmes que imposa el sistema capitalista, de manera que no se sap ben bé si les tecnologies estan al servei del capitalisme o és el capitalisme el que es va adaptant en funció dels avanços i els calendaris que aquestes marquen. Es tracta d'una relació molt complexa que genera una retroalimentació dins la qual les problemàtiques ètiques associades tant al capitalisme com a la tecnologia estan ben presents. El desafiament per a la creació de corrents de pensament crític, filosòfic i humanístic és enorme, encara que també està l'opció del silenci, que de vegades respon més a la incapacitat per construir respostes o generar nous interrogants. Davant aquest desafiament que el pensament humanista tradicional sembla no respondre amb la celeritat i flexibilitat requerides, existeix un altre model de creació de pensament i de construcció de coneixement, que també és en definitiva una nova forma de pensament humanista: allò que les arts, les pràctiques artístiques i la creació de coneixement que generen accions vinculades a l'educació artística poden aportar en aquest encreuament de relacions complex. Estudis vinculats a l'educació cognitiva situen les arts en el centre d'un model d'integració de coneixement. Les arts en general i l'educació artística en particular, impliquen noves formes d'interacció i interconnexió amb la resta del coneixement científic i humanístic, generant relacions i 
creant nous pensaments en relació a les noves tecnologies. El disseny s'articula i es connecta amb les noves tecnologies, especialment les tecnologies digitals, i amb el mateix sistema social i econòmic. El disseny és una forma de creació de pensament complex en si mateix. També la fotografia i els seus usos educatius.

Fotografia, disseny i dispositius digitals. Aquest és un escenari molt propici al concepte actual de les humanitats. Havien estat mai la filosofia, la història i la comunicació tan pròximes a l'ús indiscriminat i explosiu de les imatges? Havien estat alguna vegada les humanitats i les arts tan vinculades a la tecnologia com ho estan ara? Havíem tingut al llarg de la història algun moment propici a l'ús de les imatges a partir de la creació i la immediata difusió d'aquestes per part de la majoria de la població? No solament ha evolucionat i canviat el concepte de les humanitats i les arts, hem canviat tots els usuaris en tant que col-lectiu global, i han evolucionat els usos indiscriminats i massius de tecnologies digitals. Les humanitats, les arts i la pedagogia avancen cap a uns escenaris completament hibridats, on la tecnologia i la globalitat responen als nous models de comportament, mentre continuem ensenyant als espais formals com si les circumstàncies socials, polítiques i educatives no haguessin patit un canvi impressionant.

Cal observar el que està passant amb els usuaris de totes les edats i condicions a partir de l'ús de dispositius mòbils. En aquesta línia de treball en xarxa a partir dels usos de dispositius tecnològics, David Mascarell ens presenta una investigació a partir d'una visió polièdrica del telèfon mòbil, tot analitzant la dimensió, evolució, funció social i històrica, però també qüestionant les oportunitats que aporta aquest dispositiu que pot oferir un caràcter educatiu i artístic, a través de l'aprenentatge en mobilitat. Mascarell observa i estudia, des de la perspectiva de les arts visuals i mitjançant les imatges, una sèrie de possibilitats i propostes alternatives de treball. S'hi exposa la teoria del Mobile Learning, tot mostrant els beneficis que pot suposar l'aprenentatge mòbil i ubic en un entorn digital com és el nostre. Mascarell aposta per les oportunitats pedagògiques que cal fomentar a les aules del segle XXI, per ser conseqüents amb la realitat social i tecnològica que ens envolta.

\section{El disseny com a procés, i el museu com a entorn patrimonial digital}

Pascual Timor ens acosta als processos més actuals en les tecnologies del disseny ceràmic, que parteixen dels processos projectuals i estableixen un nou criteri de creació a partir d'arguments tecnològics com són les aplicacions i programes informàtics o la impressió en 3D. Timor ens diu que a l'aula ha sentit la necessitat de referir-se a sociòlegs i assagistes per entendre aquesta nova realitat, apostant pel mestratge del sociòleg pragmatista Richard Sennett, del qual extreu el concepte d'artesà, que es resumeix amb la idea de la «necessitat de la feina ben feta». Com que des del pragmatisme s'uneix la filosofia amb l'experiència, Sennett afirma que quan separem l'activitat pràctica de l'activitat intel-lectual, el que surt perdent és l'àmbit intel-lectual, l'àmbit d'anàlisi i la comprensió. Sennett (2013) tracta de posar en valor una qüestió injuriada pel neoliberalisme com és l'ofici i l'experiència.

Fins ara havíem viscut una obsessió per l'augment productiu, fins a l'extrem de valorar l'acceleració com un argument vàlid en el consum desproporcionat, però en aquest moment la postura de desenvolupament econòmic està ambientada en els criteris de sostenibilitat ambiental, la qual cosa comportarà dur a terme dos tipus de restriccions: 
les ecològiques (relatives a la conservació del nostre planeta) i les morals (renunciar als nivells de consum als quals no tots els individus podrien aspirar. Aquests valors estan recollits en les competències transversals que apareixen a les guies docents dels nostres títols universitaris, però la seva consecució és molt irregular, ja que l'èxit o fracàs d'un projecte encara depèn de la viabilitat econòmica, sense tenir en compte el respecte o l'impacte mediambiental. Per canviar aquest model productiu, cal revertir els valors relatius al consum, i entendre que el creixement econòmic il-limitat és incompatible amb els recursos finits del planeta. Els recursos com a patrimoni.

I si ens referim als espais educatius patrimonials, no podem perdre de vista el paper dels museus, que en aquesta ocasió són analitzats per l'historiador Ximo Aparici. Els museus han adquirit una nova dimensió com a entorns educatius no formals arran de les noves pràctiques tecnològiques i dels usos digitals. Aparici ens proposa l'anàlisi de les propostes didàctiques i els materials educatius que genera el Museu de la Seda de València. La identificació de l'ús real que se'n deriva, mitjançant enquestes i observació de les xarxes socials, permet entendre la capacitat empàtica d'aquest museu amb els usuaris, per tal d'adequar, de forma progressiva, l'oferta didàctica i cultural de l'entitat, la qual presenta una sèrie de punts forts per desenvolupar accions educatives i facilitar la seua posterior projecció digital en relació al patrimoni històric: el propi edifici, les exposicions permanents i les itinerants, així com l'arxiu gremial, el més gran i antic d'Europa que encara continua en funcionament. El patrimoni no podem entendre'l únicament des de la perspectiva material o immaterial, ja que ara tenim també l'espai digital per ficar en marxa propostes educatives i patrimonials. El fet de disposar de tots els documents digitalitzats d'aquest important arxiu ofereix als investigadors i al públic en general l'accés a documentació que fins fa ben poc estava reservada a uns pocs privilegiats. Explica Aparici que a partir d'investigacions recents s'han pogut percebre els diferents perfils del conjunt de destinataris i l'impacte que aquell patrimoni mostrat ha tingut sobre cadascun d'ells, donant pautes als museus per poder adaptar les seves estructures a les possibles necessitats d'aquests grups de destinataris tan variats. Els treballs vinculats a l'edició de fonts i documents relatius a l'àmbit que envolta el món de la seda resulten importants per poder valorar la posterior projecció didàctica d'acord als valors educatius que pretén mostrar el propi museu. Atenent als diferents nivells competencials dels destinataris, convindria passar de la mera metodologia expositiva a un plantejament d'acord amb les necessitats dels visitants que permeti un aprenentatge significatiu.

\section{Ensenyant i aprenent en digital des de la secundària a la universitat}

Els usos i pràctiques digitals estan transformant els models educatius tradicionals i també la recepció cultural a tots els nivells. En la formació de l'alumnat adolescent s'han ficat en marxa diferents mecanismes on line, de manera que els més joves ja disposen de moltes fonts d'informació i formació que van més enllà de l'aula o dels exercicis convencionals. Una professora de llengua i literatura amb anys d'experiència digital ens explica de quina manera ha pogut fer créixer el seu blog fins a l'extrem d'haver-lo convertit en un referent claríssim de l'alumnat i el professorat que s'interessa per la diversitat sexual des de la literatura en Ilengua catalana. Rosa Sanchis, autora del blog Karícies, ens explica la seva proposta educativa, una finestra al món que pretén revertir l'educació sexual que perpetua el model heterosexual hegemònic. Els eixos de la proposta tenen com a objectiu fonamental donar eines perquè els vincles afectivosexuals siguin igualitaris, per celebrar la diversitat. El treball de llengua en el blog es desenvolupa en un escenari d'interacció real 
i públic que facilita la combinació de diferents llenguatges, permet reflexionar sobre la reputació digital i la privacitat, i possibilita un acostament crític al relat audiovisual. La preeminència d'un model d'educació sexual biologicista fa que l'educació estigui centrada en la prevenció dels riscos, com ara els embarassos i les infeccions de transmissió sexual, que es consideren inherents a la sexualitat i a la seva pràctica estrella, el coit. Ens acostem a la sexualitat destacant les conseqüències negatives, i així es potencia una educació preocupada per la salut o per l'alarma social que creen els embarassos adolescents. La realitat és que patim també una erotofòbia que ignora el plaer i l'erotisme. I això resulta especialment greu en les dones, educades per a no creure en el seu dret al gaudi sexual. En una societat mediàtica, l'audiovisual adquireix un protagonisme immens. Els gèneres textuals tradicionals es transformen quan es mostren a través de la pantalla, $i$ n'apareixen de nous. Aquest fet reclama noves destreses per interactuar amb els textos, ja que hi ha molta informació que s'ha de seleccionar, valorant la fiabilitat i jutjant la utilitat. A més, cal adequar l'escriptura a aquesta nova situació comunicativa i seguir normes distintes que en regulen la interacció. Tenint en compte que la integració de les TIC en els processos d'ensenyament-aprenentatge ve determinada per llei, el professorat ha d'incloure a l'aula el tractament de la informació i la competència digital.

Si la formació de joves de secundària ha de valorar el contacte intens que tenen aquestes generacions amb la tecnologia, també a la formació universitària s'estan donant passos gegants per actualitzar formats i aspectes innovadors de continguts (Epstein, 2012). Tatiana Sentamans ens explica com s'ha organitzat un màster online de recent creació, amb tres edicions, que no solament aposta per l'entorn virtual, sinó que és la primera iniciativa de màster a l'Estat espanyol vinculada directament a les qüestions de les identitats de gènere i diversitat sexual. El màster MUECA posa en valor que els dispositius fan possible la reunió de sabers dispersos i de persones de diverses procedències i perfils, que resideixen en llocs diferents, que d'una altra manera no seria possible si no fóra gràcies a l'opció digital i a uns horaris compatibles en un sentit transcontinental (Europa/Amèrica). Els grups d'estudiants de les diferents edicions han posat en pràctica diverses estratègies de manera independent per a posar en joc el cos, fent un esforç per defendre el TFM presencialment a Altea. Això també permet conèixer-se, organitzar grups de missatgeria i xarxes privades per poder estar en contacte més enllà dels límits acadèmics, o fins i tot compartir la classe junts si residien en una mateixa ciutat, veient projectada en streaming la sessió expositiva en un mateix espai físic. Per compensar la part de distanciament digital, es fa un seguiment constant, aportant disponibilitat, immediatesa, flexibilitat i informació actualitzada.

Per a Sentamans, la clau és l'interès del projecte, que mou a un alumnat molt motivat per les qüestions LGTB, i que de fet ha estat reconegut institucionalment amb l'obtenció del finançament màxim de la convocatòria de subvencions destinades a la realització de postgraus d'Estudis de Gènere, la qual cosa ha permès sufragar les taxes de tots i totes les estudiants. Així mateix, l'aplicabilitat per a la intervenció social, en l'àmbit propi de MUECA, ha sigut reconeguda amb el Premi Museari 2019 per les accions en favor de la visibilitat i els drets de la diversitat sexual (Navarro, 2019).

Pel que fa als resultats obtinguts per l'alumnat, s'ha d'assenyalar que es tracta d'una proposta de contra-productivitat, en la que prima la qualitat versus la quantitat. Convé destacar, des del punt de vista de la memòria, l'arxiu i la visibilitat de les genealogies fe- 
ministes i cuir/queer de resistència, l'arxiu documental LGTB de la ciutat de Sabadell complementat amb entrevistes audiovisuals; s'ha elaborat una genealogia de les dones en l'àmbit del disseny gràfic (disenadorasgraficas.com), i també una cartografia que documenta la historiografia dels escenaris queer-transfeministes en el món rural de la província d'Alacant, que a través de tallers, entrevistes i anàlisis documentals explicita les tensions, produccions i canvis que se succeeixen. A més, s'han dissenyat eines feministes i queer per desconstruir la mirada cisgènere en la representació de narratives fílmiques transgènere en el context llatinoamericà. Comprovem que MUECA combina a la perfecció les humanitats digitals amb les pedagogies culturals.

\section{Conclusions}

Tenint en compte la realitat educativa en la qual ens movem, que és múltiple, ubiqua, transversal, transdisciplinar i també digital, i valorant el gran impuls que demostren les arts i les humanitats des de l'òrbita digital, podem pensar que encara tenim molts entorns per descobrir que conjugaran la realitat geogràfica i física amb els entorns online i els dispositius tecnològics. Es pregunta Ana María González si les tecnologies són humanes, tot dirigint-se cap a una fonamentació de gènere ètic de la utilització massiva de les xarxes socials. Les xarxes formen part intrínseca del món digital, i per tant cal estar molt atents als models que neixen i als que ja formen part de la quotidianitat de la ciutadania. No es tracta solament d'educar en qüestions tecnològiques, sinó també d'educar en el valors que propicia la deriva tecnològica.

L'ús massiu de les tecnologies, així com la participació en xarxes socials i les aplicacions mòbils, semblen dirigits a proporcionar una extensió d'humanitat que les eines digitals no tenen realment. Les tecnologies de la informació i la comunicació suposen nous reptes per a la ciutadania, ja que se'n fa un ús massiu per part de la població, habitualment sense iniciar una reflexió conscient i responsable. Les nombroses utilitats i funcions recreatives han convertit la tecnologia en un instrument familiar i quotidià. Les tecnologies semblen haver adquirit un estatut humà, però la diferència és la responsabilitat ètica que hauria de predominar. Les desigualtats es reprodueixen si no hi ha un esforç conscient i decidit per eliminar-les i superar-les. És urgent que les humanitats digitals abordin totes les dimensions des d'un enfocament interseccional amb la finalitat de relacions més igualitàries i menys discriminadores en les xarxes socials. Es tractaria d'aconseguir espais segurs, de manera que la població pugui mesurar l'impacte, tingui la capacitat crítica per identificar vulnerabilitats de seguretat, situacions de discriminació, i sigui capaç de respondre adoptant patrons de conducta des de la seguretat.

Les humanitats no només han d'explicar quines són les relacions que amaga l'ús de les tecnologies en el conjunt de la societat i entre els ciutadans, sinó que han avançar-se a la seva utilització, reflexionant sobre els impactes desitjables i no desitjables que provoquen. Aquesta visió ha estat adoptada per algunes branques de les ciències tecnològiques i d'enginyeries, allà on s'estableix com a principi primordial el disseny centrat en l'usuari, tot i que el nivell d'aplicació d'aquest principi només suposa preguntar a la població si vol involucrar-se en el seu disseny. El paper de les ciències socials i humanes ha de complir tres funcions fonamentals lligades a les esferes social, ètica i educativa, les quals col-lectivament han de donar origen a la sobirania del coneixement. 


\section{Referències}

Cilliers, E.J. (2017) «The challenge of teaching generation Z». People: International Journal of Social Sciences, 3 (1), p. 188-198, DOI: 10.20319/pijss.2017.31.188198.

Domínguez, R. (2019) Entornos personales de aprendizaje en la formación de docentes de Secundaria de la especialidad de Dibujo. Tesi doctoral. Universitat de València, València.

Epstein, M. (2012) The Transformative Humanities. A Manifesto. London, Bloomsbury.

Francis, T. i Hoefel, F. (2018). «True Gen': Generation Z and its implications for companies» https://www.mckinsey.com/industries/consumer-packaged-goods/ourinsights/true-gen-generation-z-and-its-implications-for-companies

Huerta, R. i Alonso-Sanz, A. (ed.) (2017) Entornos informales para educar en artes. Publicacions de la Universitat de València, València.

Huerta, R. i Domínguez, R. (2011) «Las TIC en la formación de docentes de la especialidad de dibujo. La propuesta "aula infinita" para el nuevo master universitario de profesorado en Educación Secundaria». EDUTEC. Revista Electrónica de Tecnología Educativa, 36, p. 1-14. doi:10.21556/edutec.2011.36.399

Levin, D. (2019) «Generation Z: Who They Are, in Their Own Words»: https://www.nytimes.com/2019/03/28/us/gen-z-in-their-words.html

Mascarell, D. (2017) Les TIC en la formació universitària de mestres. El telèfon mòbil en la Didàctica de l'Expressió Plàstica a la Facultat de Magisteri de la Universitat de València. Tesi doctoral. Universitat de València.

Navarro, G. (2019) Museari Queer Art: el projecte Arteari en Las Naves. València, Espai d'Art Fotogràfic.

Roig-Vila, R., Mengual-Andrés, S., Sterrantino, C. i Quinto, P. (2015) «Actitudes hacia los recursos tecnológicos en el aula de los futuros docentes». @tic. revista d'innovació educativa, 15, p. 12-19. doi:10.7203/attic.15.7220

Sennett, R. (2013) El artesano. Barcelona, Anagrama.

Suárez-Guerrero, C., Lloret-Catalá, C. i Mengual-Andrés, S. (2016) «Percepción docente sobre la transformación digital del aula a través de tabletas: un estudio en el contexto español». Comunicar, 24(49), p. 81-89. doi: https://doi.org/10.3916/C49-2016-08

Trifonas, P. P. i Jagger, S. (ed.) (2019) Handbook of Cultural Studies and Education. NY., Routledge.

Yin, R. K. (2009) Case study research: design and methods. California, Sage. 


\section{Humanidades digitales y pedagogías culturales: miradas cruzadas a los entornos educativos híbridos}

Resumen: Las artes y las humanidades están viviendo un rápido proceso de evolución y de cambios gracias al crecimiento del universo digital. La educación no está exenta de transformaciones profundas, motivadas por el impacto de esta realidad virtual que ya es local y global, que es ubicua y nos afecta a todos. Como formadores de docentes, analizamos hasta qué punto las hibridaciones de ambos escenarios (las humanidades digitales y las pedagogías culturales) están favoreciendo un clima integrador y de superaciones, o bien propician un nuevo modelo de abusos y excesos hacia el profesorado y el alumnado. Mirando la situación en positivo, observamos que la huella digital puede ayudar a romper las barreras tradicionales que habían sido marcadas por las áreas de conocimiento, superando así el encasillamiento tradicional de asignaturas, posibilitando escenarios conectados desde la transversalidad. Nos interesa conocer los diferentes modelos híbridos que favorece el entramado digital, implicando artistas, educadores en artes, historiadores, lingüistas y diseñadores, que nos muestran sus particulares visiones de este nuevo modelo de escenarios educativos conectados.

Palabras clave: Humanidades digitales, pedagogías culturales, arte, educación, formación del profesorado, género.

\section{Humanités digitales et pédagogies culturelles: regards croisés sur des environnements éducatifs hybrides}

Résumé: Les sciences humaines et les arts traversent une période d'évolution et de changements rapides grâce à la croissance de l'univers numérique. L'éducation vit, elle aussi, des transformations profondes, dues également à l'impact de cette réalité virtuelle qui est désormais locale et globale, omniprésente et qui nous touche tous. En tant qu'enseignants et formateurs d'enseignants, nous nous intégrons dans ce processus afin d'analyser dans quelle mesure les hybridations de ces deux scénarios (les sciences humaines numériques et les pédagogies culturelles) créent un climat propice à l'intégration et au dépassement, ou favorisent un nouveau modèle d'abus et d'excès à l'égard des enseignants et des élèves des différentes étapes éducatives. Si l'on considère la situation d'un point de vue positif, on observe que l'empreinte numérique peut aider à briser les barrières traditionnelles qui avaient été dressées par les domaines de connaissance spécifiques, et à surmonter ainsi la catégorisation traditionnelle de matières et d'enseignements concrets, en faisant émerger des scénarios connectés de manière transversale. C'est pourquoi nous souhaitons connaître les différents modèles hybrides favorisés par le réseau numérique, impliquant artistes, éducateurs en arts, historiens, linguistes et créateurs, qui nous montrent leurs visions particulières de ce nouveau modèle de scénarios éducatifs connectés.

Mots clés: Sciences humaines numériques, pédagogies culturelles, art, éducation, formation des enseignants, genre.

\section{Digital Humanities and Cultural Pedagogies: cross-views of hybrid educational environments}

Abstract: The arts and the Humanities are experiencing a rapid process of evolution and change thanks to the growth of the digital universe. Education is also undergoing profound transformations, also motivated by the impact of this virtual reality which is already both local and global, ubiquitous, and affects us all. As teacher trainers, we analyse the hybridizations of the two scenarios of digital humanities and cultural pedagogies which can either create an integrative climate geared towards achievement, or, in the worst case, foster a new model of abuse and excess towards teachers and students at different stages of education. Looking at the situation, we observe that the digital dimension can help to break down the traditional barriers that have been imposed by specific areas of knowledge, and can help to achieve connected scenarios. Here we are interested in the different hybrid models, involving artists, arts educators, historians, linguists and designers, who show us their particular visions of this new model of connected educational contexts.

Keywords: Digital Humanities, Cultural Pedagogies, Art, Education, Teacher Training, Gender. 